\title{
Cerebellar Cortical AMPA-Kainate Receptor Blockade Prevents Performance of Classically Conditioned Nictitating Membrane Responses
}

\author{
P. J. E. Attwell, S. Rahman, M. Ivarsson, and C. H. Yeo \\ Department of Anatomy and Developmental Biology, University College London, London WC1E 6BT, United Kingdom
}

Classical conditioning of the nictitating membrane-eye blink response of rabbits is a simple form of associative motor learning. Lesion studies have shown that performance of learned responses is dependent on the cerebellum, but they have not shown whether there is storage of memories within the cerebellum or distinguished the roles of the cerebellar cortex and nuclei. Reversible inactivations of the cerebellar nuclei have directly implicated the cerebellum in the acquisition of nictitating membrane conditioning, but previously the cerebellar cortex has not been reversibly inactivated to assess its contribution to the performance or acquisition of conditioned responses. Here we use the water-soluble disodium salt of 6-cyano-7-nitroquinoxaline-2,3-dione (CNQX) reversibly to block cerebellar cortical AMPA-kainate receptors in lobule HVI

The role of the cerebellum in the acquisition and performance of motor skills is still a controversial issue (Ito, 1998; Thach, 1998; Yeo and Hesslow, 1998). Classical conditioning of the rabbit eye blink-nictitating membrane response (NMR) is a simple form of motor learning. Lesion studies of NMR conditioning have been useful in identifying important cerebellar nuclear regions in the anterior interpositus nucleus (McCormick and Thompson, 1984; Yeo et al., 1985a; Welsh and Harvey, 1989) and cortical regions in lobule HVI (Yeo et al., 1985b; Yeo and Hardiman, 1992) (but see Lavond et al., 1987; Perrett et al., 1992). But lesions have not revealed whether there is storage of motor memories within the cerebellum, because they can affect performance rather than learning itself (Welsh and Harvey, 1989, 1991).

Recent studies using reversible lesions dissociate learning and performance effects. Conditioning trials are given during discrete cerebellar inactivations. An absence of conditioned responses (CRs) after recovery from the inactivation indicates that the affected circuitry is directly involved in acquisition or storage of the learning. An initial study using lidocaine blockade (Welsh and Harvey, 1991) indicated that the cerebellar nuclei are not critically involved in acquisition of NM conditioning to a second CS, but all subsequent studies using either the $\mathrm{GABA}_{\mathrm{A}}$ agonist muscimol or lidocaine have shown that the cerebellar nuclei are critical for de novo acquisition (Krupa et al., 1993; Nordholm et

\footnotetext{
Received July 8, 1999; revised Oct. 7, 1999; accepted Oct. 14, 1999.

This study was supported by Biotechnology and Biological Sciences Research Council Grant 31/S10225. We thank Dr. Richard Hawkes for his generous gift of the Zebrin II antibody.

Correspondence should be addressed to Dr. P. J. E. Attwell, Department of Anatomy and Developmental Biology, University College London, London WC1E 6BT, UK. E-mail: p.attwell@ucl.ac.uk.

Copyright (C) 1999 Society for Neuroscience $\quad 0270-6474 / 99 / 190001-\bullet \$ 05.00 / 0$
}

and quantitative autoradiography to map its distribution. Conditioned responses are completely, but reversibly, abolished for 10-60 min depending on the concentration of the CNQX infusion and its location within HVI. Zebrin immunohistochemistry was used to define the optimal cortical infusion site that, we suggest, corresponds to the location of the eye blink control regions. We confirm that areas in $\mathrm{HVI}$ are essential for the expression of classically conditioned nictitating membrane responses, and we establish a method to analyze the role of cerebellar cortex in the acquisition of this form of motor learning.

Key words: classical conditioning; eye blink; cerebellar cortex; AMPA receptors; reversible inactivation; motor learning

al., 1993; Hardiman et al., 1996) and extinction (Hardiman et al., 1996; Ramnani and Yeo, 1996) of NMR conditioning. Because inactivation of olivary inputs to the cerebellum prevents NMR acquisition (Welsh and Harvey, 1998), but inactivation of cerebellar efferents in the brachium conjunctivum does not (Krupa and Thompson, 1995), the cerebellum is now strongly implicated in the acquisition and storage of information critical for NMR conditioning. It is not yet resolved whether essential plasticity is within the cerebellar cortex, in the cerebellar nuclei, or in precerebellar structures (for review, see Thompson and Krupa, 1994; Yeo and Hesslow, 1998). Neither is it clear whether essential plasticity is distributed at two or more of these levels or is dependent on interactions between them (Mauk and Donegan, 1997).

Most theories of cerebellar motor learning propose that there is essential plasticity at the parallel fiber $\rightarrow$ Purkinje cell synapses of the cerebellar cortex (Marr, 1969; Albus, 1971; Ito, 1998). Although previous inactivation studies would have disturbed cerebellar cortical activity indirectly by disrupting the olivo-corti-

This article is published in The Journal of Neuroscience, Rapid Communications Section, which publishes brief, peerreviewed papers online, not in print. Rapid Communications are posted online approximately one month earlier than they would appear if printed. They are listed in the Table of Contents of the next open issue of JNeurosci. Cite this article as: JNeurosci, 1999, 19:RC45 (1-6). The publication date is the date of posting online at www.jneurosci.org.

http://www.jneurosci.org/cgi/content/full/3775 
co-nuclear loop, cerebellar cortex has not been targeted directly with reversible inactivations to test its role in the performance or acquisition of NMR conditioning. In the present study, we have used a water-soluble form of the non-NMDA ionotropic glutamate receptor antagonist 6-cyano-7-nitroquinoxaline-2,3-dione (CNQX) to test the effects of blocking glutamatergic transmission within NM-eye blink control areas in lobule HVI during performance of NM conditioned responses. The experiment allows localization of the eye blink control areas within HVI and provides a method for reversible inactivations that can be used directly to determine whether memories for NMR conditioning are stored within the cerebellar cortex.

\section{MATERIALS AND METHODS}

\section{Surgery}

Six male Dutch belted rabbits $(1.8-2.5 \mathrm{~kg})$ were implanted with a guide cannula directed toward the right cerebellar lobule HVI. Subjects were anesthetized using a fentanyl-fluanisone mixture $(0.1-5.0 \mathrm{mg} / \mathrm{kg}$, i.m.) with benzodiazepam ( $0.5 \mathrm{mg} / \mathrm{kg}$, i.v.). Mannitol (20\%, w/v, $30 \mathrm{ml}$ over 30 min, i.v) was given to facilitate exposure of the cerebellum. Then, anesthesia was by fluothane $(1-2 \%)$ in oxygen/nitrous oxide (2:1). A cranial opening exposed cerebellar cortex and a $26 \mathrm{ga}, 11 \mathrm{~mm}$ stainless steel guide cannula was implanted into the right HVI and fixed with acrylic cement. A 33 ga dummy cannula fitted into the guide kept the implant patent. Postoperative analgesia (buprenorphine, $100 \mu \mathrm{g} \cdot \mathrm{kg}^{-1} \cdot \mathrm{d}^{-1}$, i.m.) and antibiotic cover (chloramphenicol $30 \mathrm{mg} \cdot \mathrm{kg}^{-1} \cdot \mathrm{d}^{-1}$, i.m.) were given for $3 \mathrm{~d}$. Subjects were allowed 1 week of recovery and kept on a $12 \mathrm{hr}$ day/night cycle with ad libitum food and water.

\section{Conditioning apparatus and stimuli}

Rabbits were trained using techniques similar to those first developed by Gormezano et al. (1962) and described in detail by Yeo and Hardiman (1992). Subjects were placed in a restraining stock, and movement of the NM was recorded using an isotonic transducer (Gruart and Yeo, 1995).

Each subject was placed in a ventilated, sound-attenuating chamber facing a centrally mounted loudspeaker. The CS was a $1 \mathrm{kHz}$ sine wave tone of 410 msec duration and an intensity of $87 \mathrm{~dB}$. Background noise produced by ventilation fans was $57 \mathrm{~dB}$. The unconditioned stimulus (US) was periorbital electrical stimulation. Each US was a $60 \mathrm{msec}$ train of three biphasic current pulses $(2 \mathrm{~mA})$ applied to the periorbital region. The interstimulus interval between the CS and US onsets on paired trials was $350 \mathrm{msec}$. The intertrial interval was randomly selected between 25 and $35 \mathrm{sec}$.

\section{Experimental design}

Five to $7 \mathrm{~d}$ after cannula guide implantation, a nylon monofilament suture loop was placed in the right NM under local anesthesia (proxymetacaine hydrochloride; $0.5 \%, \mathrm{w} / \mathrm{v}$ ). All subjects then underwent four daily sessions of adaptation. Each subject was placed in the restraining stock within the conditioning chamber, and the NM transducer was fitted. Each subject rested quietly in the conditioning chamber for $50 \mathrm{~min}$, equivalent to the duration of one conditioning session, and no stimuli were presented.

\section{Three main experimental phases}

(1) Acquisition training. Each subject received six sessions (1/d) of normal acquisition training to establish stable performance. Each session consisted of 100 trials. In 90 trials the CS and US were paired, and in 10 trials the CS was presented alone with no US. Each CS-alone trial was presented on every 10th trial.

(2) Establishing an optimal locus for cortical infusions. The dummy cannula was removed, and a sterile, 33 ga infusion cannula was inserted through the guide to project $1 \mathrm{~mm}$ below the guide tip. No drug was infused at this stage. Twenty training trials (18 paired CS-US and 2 CS-alone) were given to establish a preinfusion behavioral baseline. Each subject then received an inf usion of CNQX (disodium salt; Tocris Cookson, Bristol, UK; $5 \mathrm{~mm}, 1 \mu \mathrm{l}$ inf used over $1 \mathrm{~min})$ in PBS $(0.01 \mathrm{M}, \mathrm{pH}$ 7.4). Fifty training trials (45 CS-US paired and 5 CS alone) were then given. $\mathrm{CR}$ frequency was monitored. If $\mathrm{CR}$ frequencies did not fall to zero over nine consecutive trials within the session, then a 30 min rest period was given. The inf usion cannula was then lowered by $0.5 \mathrm{~mm}$, and the infusion and testing procedures were repeated. In each subject a maximum of four cannula positions (from 1 to $2.5 \mathrm{~mm}$ below the guide tip) were tested over $2 \mathrm{~d}$ to find the most effective location.

(3) Testing time course of drug effects and dose-response relationships. Each subject was prepared as in phase 3 above, and the infusion cannula was lowered to the optimal depth determined earlier. Twenty training trials (18 paired CS-US and 2 CS-alone) were given to establish a preinfusion behavioral baseline. Each subject then received an infusion of CNQX in PBS vehicle (either 1.54 or $5 \mathrm{~mm}, 2 \mu \mathrm{l}$ inf used over $2 \mathrm{~min}$ ) or a control infusion of PBS vehicle (0.01 M, pH 7.4, $2 \mu$ linf used over 2 min). After a short interval (mean, $5 \mathrm{~min}$; range, 3-12 min) a training session of 50 trials commenced. If CR frequencies had not returned to preinfusion levels at the end of 50 trials, a further 50 trials were given. The order in which low-dose CNQX, high-dose CNQX, and PBS was infused varied across subjects.

\section{Histology}

In the final stage of the experiment infusion cannulae were reinserted to the individual optimal depth. $\left[{ }^{3} \mathrm{H}\right] \mathrm{CNQX}$ in PBS (1.54 mm containing 1 $\mu \mathrm{Ci} / \mu \mathrm{l}, 2 \mu \mathrm{l}$ over $2 \mathrm{~min}$ ) was infused. This corresponds to the lower of the two concentrations used in the experimental phase. Each subject was then given heparin sodium (500 U/kg, i.v.) and an overdose of pentobarbitone sodium (90 mg/kg, i.v.) $12 \mathrm{~min}$ after the end of the CNQX infusion. This time was chosen with reference to the time course data (see Fig. 2) and corresponds to the time for maximum drug effect on behavior. Each subject was perfused transcardially with $0.9 \%$ saline (1 1$)$ followed by $4 \%$ formaldehyde solution (2 1). The brain was removed, embedded in gelatin, and cryoprotected in $20 \%$ sucrose solution, and then serial, $50 \mu \mathrm{m}$ frozen transverse sections were cut.

\section{Autoradiography and image analysis}

Every sixth brain section was opposed to tritium-sensitive film (Hyperfilm; Amersham Pharmacia Biotech, Uppsala, Sweden) for autoradiography together with tritium standards (Microscales; Amersham Pharmacia Biotech) for 6 weeks at $4^{\circ} \mathrm{C}$. After film development, the sections were stained with cresyl violet. The autoradiograph of every brain section was imaged with a monochrome CCD camera and analyzed using standard densitometry techniques (AIS; Imaging Research, St. Catharines, Ontario, Canada); the resultant images were calibrated, and their densities were color-coded with reference to the tritium standards as picomoles of CNQX per milligram of tissue equivalent (see Fig. 1).

The stained sections were realigned to allow registration of the histology and autoradiography. An image of each Nissl-stained section was captured and was processed to reveal the brain edges and granule cell layer boundaries. Composites of the color-coded densitometry and the brain contours were then made.

\section{Zebrin immunohistochemistry}

Every sixth brain section was left unmounted and used for immunohistochemistry. Throughout, all dilutions and washes used $0.01 \mathrm{M}$ PBS containing $0.5 \%$ Triton X-100 and $0.05 \%$ thimerosal (Sigma, St. Louis, MO) unless otherwise stated. The sections were incubated in $0.1 \%$ hydrogen peroxide for $15 \mathrm{~min}$ and then placed in 5\% normal horse serum (NHS) for $30 \mathrm{~min}$. They were incubated for $14 \mathrm{hr}$ at $4^{\circ} \mathrm{C}$ in $0.1 \%$ Zebrin II antibody (Brochu et al., 1990). Then the sections were washed, placed in $5 \%$ NHS for $30 \mathrm{~min}$, and incubated in biotinylated horse anti-mouse $\operatorname{IgG}(1: 200)$ for $2 \mathrm{hr}$ at room temperature. Sections were washed again and immersed in streptavidin-HRP (1:200) for $2 \mathrm{hr}$. Then they were washed, buffered with Tris (Sigma; $\mathrm{pH} 7.4,1: 20$ ), and incubated with diaminobenzidine $(0.03 \%$, w/v, in $0.01 \%$ hydrogen peroxide-Tris buffer) until Zebrin-positive stripes were clearly revealed. Then the sections were washed, mounted, and coverslipped.

\section{Data analysis}

$C R$ frequency. A CR was defined as an NM response within the CS-US interval with amplitude $\geq 0.5 \mathrm{~mm}$ and with onset latency $>35 \mathrm{msec}$ from CS onset (Hardiman and Yeo, 1992). CR frequency (percent CRs) was calculated for each block of nine paired trials throughout the conditioning sessions.

CR topographies. $\mathrm{CR}$ amplitude measurements were made on CS-alone trials only. This measure was able to reveal whether the drug produced $\mathrm{CR}$ latency increases that would have been obscured on paired trials. On these trials, a CR was defined as a response that attained an amplitude $\geq 0.5 \mathrm{~mm}$ in the period $35-1000 \mathrm{msec}$ from CS onset. 

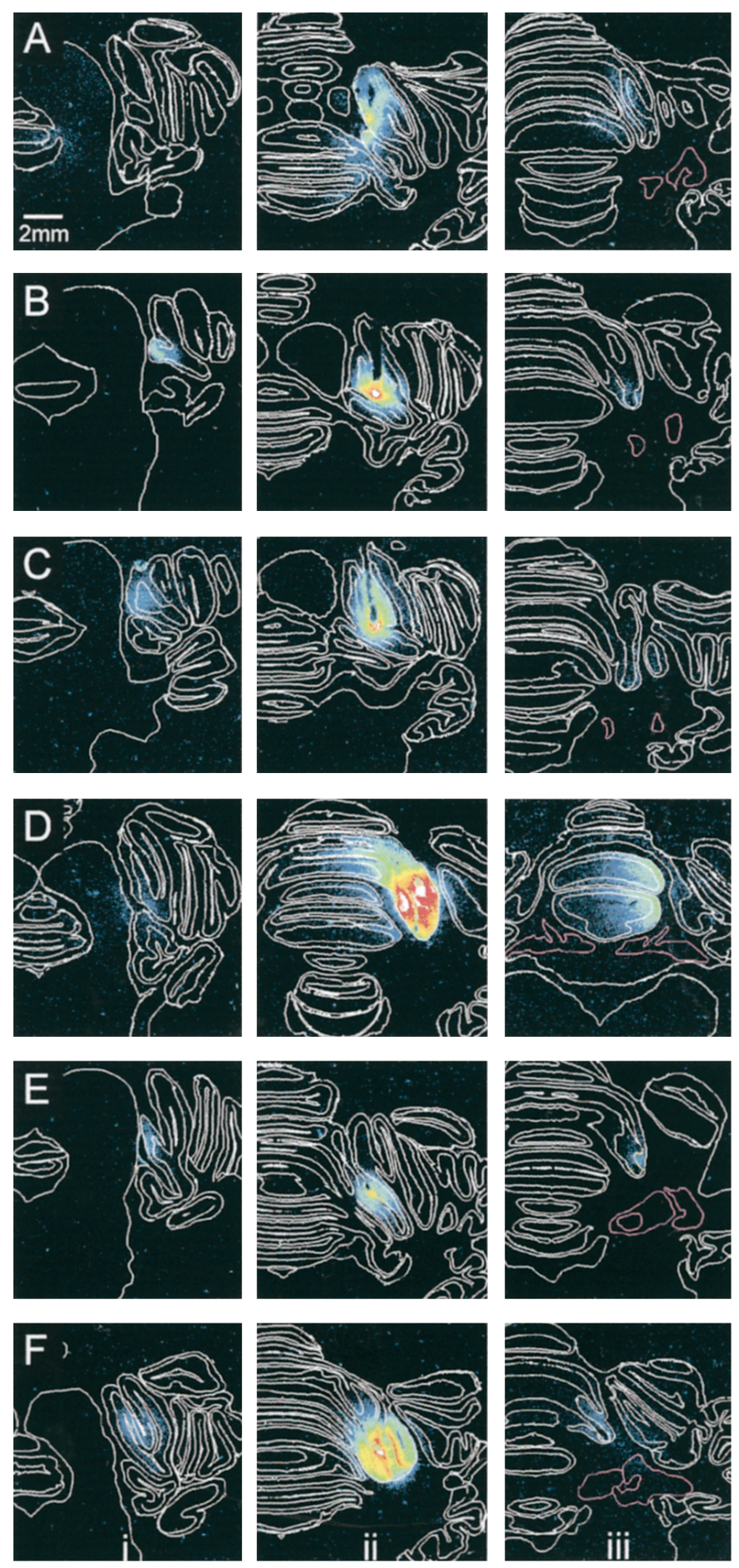
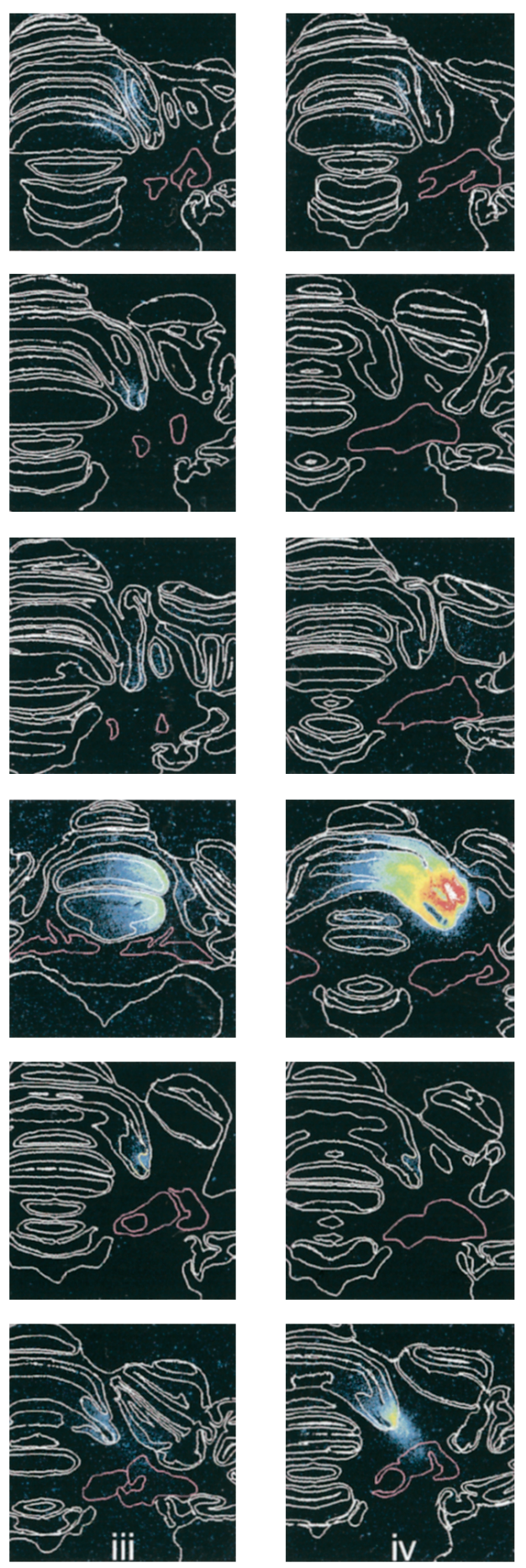
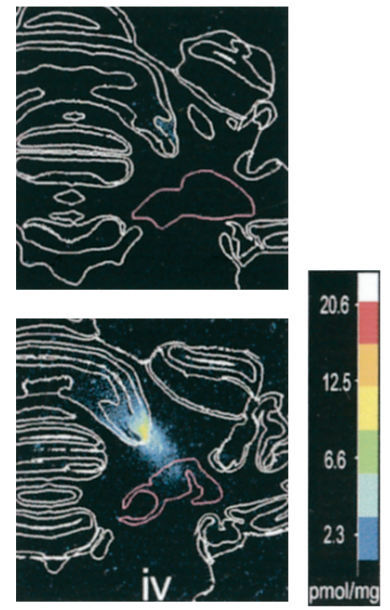

Figure 1. $\left[{ }^{3} \mathrm{H}\right] \mathrm{CNQX}$ distribution in cerebellar cortex after localized infusion into lobule HVI. Subjects $A-E$ are ranked by CNQX effects on behavior; $A$ is most affected. Columns $i$ and iii show the most rostral and caudal levels with CNQX binding; ii shows the infusion center, and $i v$ shows the cerebellar nuclei ( pink boundaries). Subject $F$ has low levels of CNQX in the cerebellar nuclei. Lobule and granule cell boundaries are shown in white. Densitometry calibration, picomoles of CNQX per milligram of tissue equivalent.

\section{Statistical analysis}

Data were analyzed using a two-way, repeated measures ANOVA followed, where appropriate, by Newman-Keuls multiple-comparisons test on the individual means.

\section{RESULTS}

\section{Autoradiography revealed that CNQX infusions were} restricted to cerebellar cortex

Autoradiography of $\left[{ }^{3} \mathrm{H}\right] \mathrm{CNQX}$ binding revealed the infusion center and its spread. In all subjects, the infusion center was in lobule HVI, but its location varied in the rostral-caudal direction across subjects (Fig. 1). Subjects A-E are ranked according to the duration of CNQX (1.54 mm) effects on CRs (see below). In subject $\mathrm{A}, \mathrm{CR}$ impairment duration was longest; in subject $\mathrm{E}$ it was shortest. In subjects A-E, all CNQX detected was within the cerebellar cortex with no observed binding within the deep cerebellar nuclei at any location. By observation of the rank order, it may be seen that CNQX infusions in the rostral part of medial lobule HVI most impaired CR frequency. Subject D had an infusion in the very caudal part of lobule HVI with spread into other lobules including VII and VIII, yet its percent CRs were not as impaired as those of subjects A-C. Subject E had an 


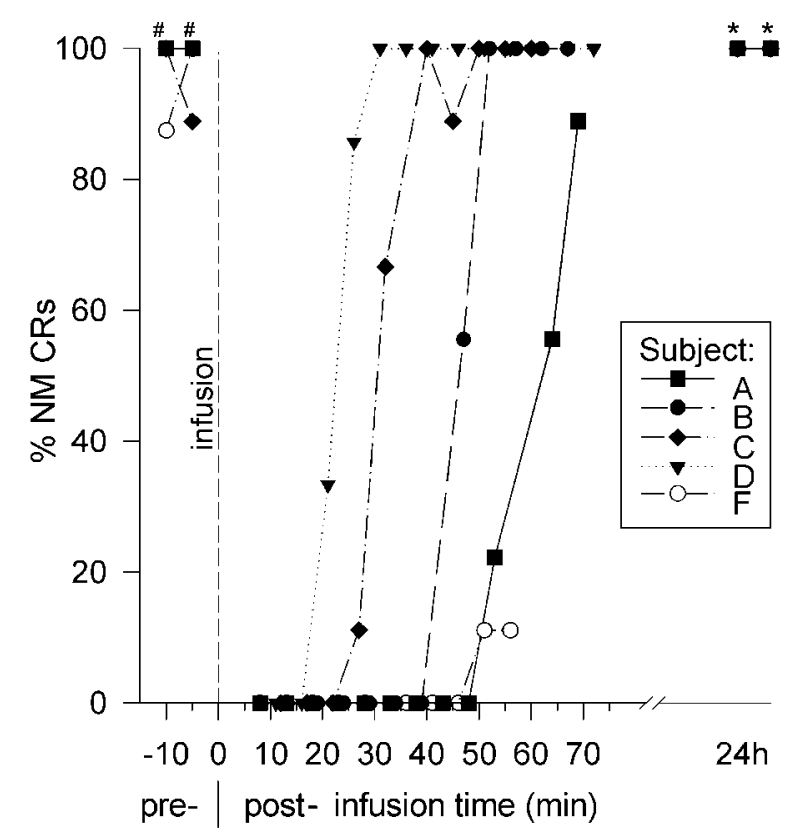

A

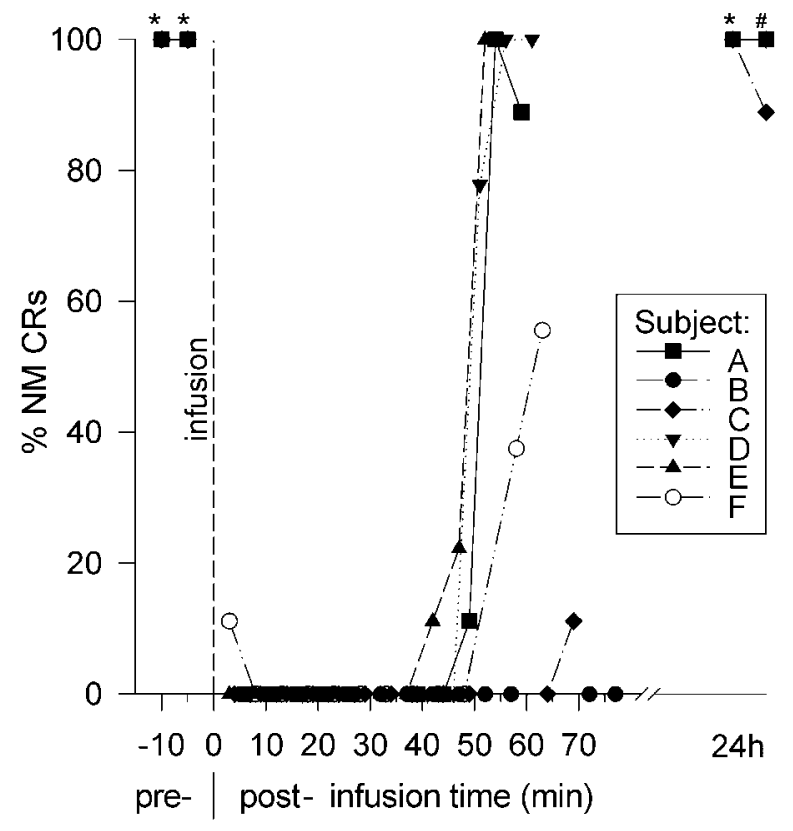

B

Figure 2. Effects of cerebellar cortical CNQX on NM CR frequency in individual subjects. Percent CRs are given for each subject before and after infusion of $2 \mu \mathrm{l} \mathrm{CNQX}$ at either a $1.54 \mathrm{~mm}(A)$ or $5 \mathrm{~mm}(B)$ concentration. *Overlapping points, all subjects; ${ }^{\#}$ overlapping points, some subjects.

infusion of CNQX in only a small part of the very medial part of rostral lobule HVI with spread into lobules HIV-V of the anterior lobe that produced the smallest percent $\mathrm{CR}$ deficits. There were very low levels of CNQX binding in small regions of the caudal inferior colliculus (IC) in subjects A and D. It is unlikely that these very low levels of CNQX in the IC contribute to CR deficits to the auditory CS, because infusions of high levels of CNQX directly into IC do not impair CR frequency (our unpublished observations). Subjects A-E form the cerebellar cortical infusion (CCI) group in the behavioral analyses below.

In subject $\mathrm{F}$, there was clear CNQX binding in lobule $\mathrm{HVI}$, but there were also low levels of CNQX binding within the dentateinterpositus nucleus border, a cerebellar nuclear area that is critical for CR expression (McCormick and Thompson, 1984; Yeo et al., 1985a). To clarify the behavioral effects of purely cerebellar cortical manipulations, the individual behavioral data for this subject is presented below, but it is not included in the CCI group behavioral analysis.

\section{AMPA-kainate receptor antagonist blocked CR expression}

CNQX infusions restricted to the cerebellar cortex (in the CCI group subjects) completely blocked CR expression, although the duration of the drug effects varied across subjects and by dose (Fig. 2).

All subjects (A-F) reached a stable level of learning (at least eight CRs in the nine paired presentations per block) by 370 trials (198.3 \pm 39.9 , mean \pm SEM) before drug infusions.

In the CCI group, infusion of vehicle directly into parts of lobule HVI had no effect on CR responses (Fig. $3 A, B$ ). In the same subjects, CNQX infusions restricted to lobule HVI produced significant changes in the frequency (Fig. 3A, \% NM CRs) and the amplitude of CRs (Fig. 3B, CR amplitude) $\left(F_{(2,153)}=39.0\right.$; $p<0.001$; and $F_{(2,153)}=26.73 ; p<0.001$, respectively). For all CCI subjects, CRs were completely absent for at least two blocks of trials (corresponding to $10 \mathrm{~min}$ ). For $1.54 \mathrm{~mm}$ infusions, the mean number of blocks with no CRs was 5.4 (range, 2-9) corresponding to a mean time of $27 \mathrm{~min}$ (range, 10-45 min). For $5 \mathrm{~mm}$ infusions, the mean number of blocks with CR abolition was 8.8 (range, 7-12), corresponding to $44.2 \mathrm{~min}$ (range, 35-60 $\mathrm{min}$ ).

Both concentrations of CNQX reduced CR frequencies and amplitudes (Fig. 3). After infusions of CNQX at $1.54 \mathrm{~mm}$ concentration, percent CRs were significantly different from those seen after vehicle infusion at equivalent time points within the first $35 \mathrm{~min}(p<0.05$, Newman-Keuls multiple-comparisons test). For $5 \mathrm{~mm} C \mathrm{CNQX}$ infusions, the effects on percent $\mathrm{CR}$ were significant for the entire $50 \mathrm{~min}$ session duration $(p<0.05)$. Similar changes were seen for CR amplitude, with significant differences $(p<0.05)$ for the $1.54 \mathrm{~mm}$ concentration over the first 20 min and for the entire session with 5 mM CNQX $(p<0.05)$.

Most subjects recovered both percent CRs and CR amplitude within $1 \mathrm{hr}$ of drug administration, with no residual effects at 24 hr (Fig. 2A,B). Percent CRs recovered sooner after infusion of $1.54 \mathrm{~mm}$ CNQX than $5 \mathrm{~mm}$ CNQX. Percent CRs were significantly different for the two doses from 30 min after inf usion $(p<$ $0.05)$, and CR amplitude differences were significant at $40 \mathrm{~min}$ $(p<0.05)$.

The single subject, F, with minor spread of CNQX into the cerebellar nuclei had strongly depressed CR frequencies after 1.54 and $5 \mathrm{~mm}$ infusions. Although this subject had high CNQX levels in rostral HVI, it cannot be ruled out that at least some of these behavioral deficits derive from AMPA-kainate receptor blockade in the nuclei.

\section{Zebrin immunohistochemistry defined anatomical boundaries of effective CNQX infusion sites}

Zebrin II immunohistochemistry revealed clear zonal patterns of immunopositive and immunonegative bands throughout the cerebellar cortex that were consistent across subjects. Three zebrinpositive bands were revealed in HVI coronal sections. These three bands appear to correspond to zebrin zones $\mathrm{P} 4+, \mathrm{P} 5+$, and P6 + that have already been defined in the rat (Brochu et al., 1990; 

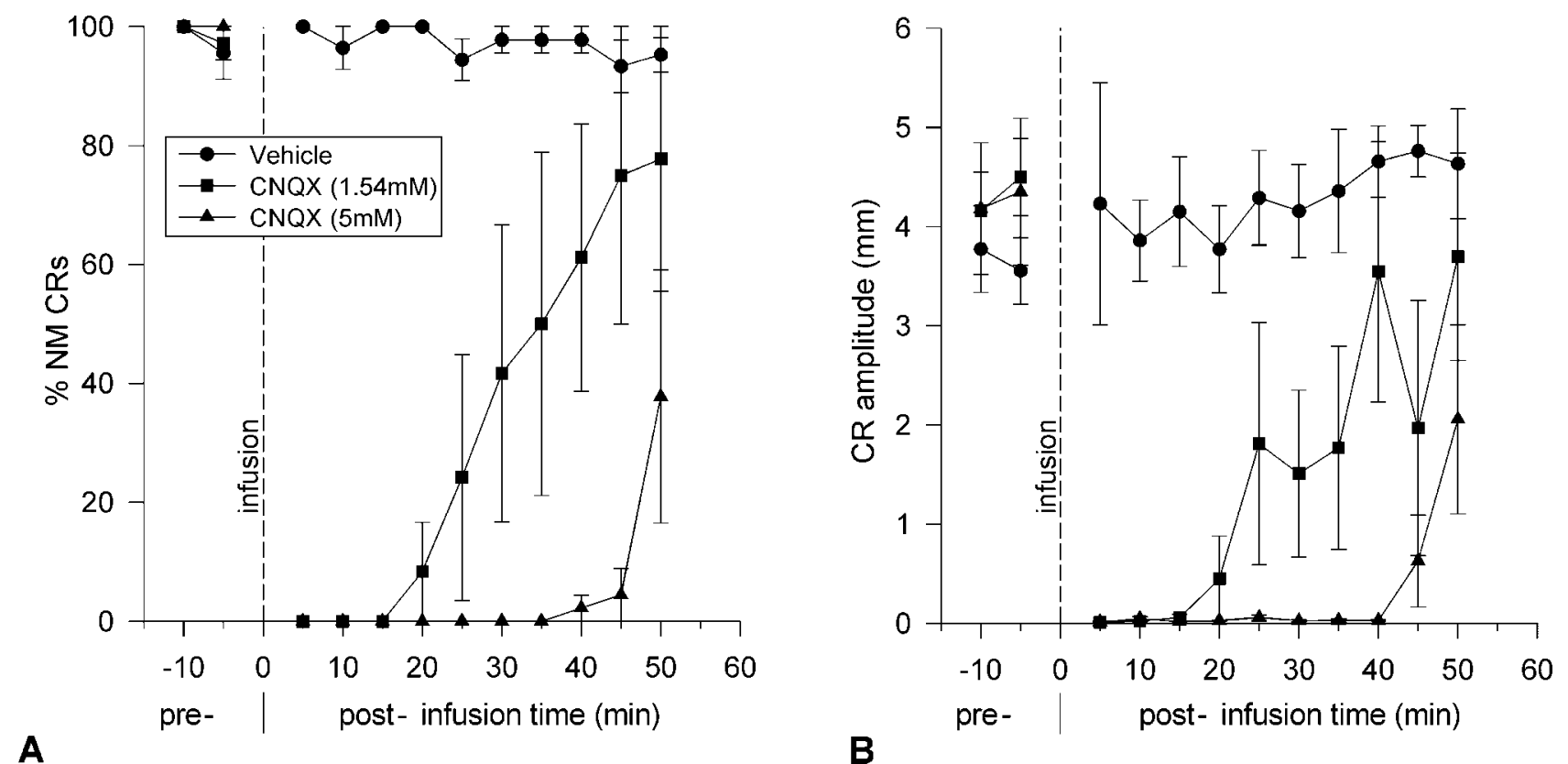

Figure 3. Time course of cerebellar cortical CNQX effects on NM CR frequency and amplitude. $A$, CCI group mean percent CRs \pm SEM. $B$, CCI group mean CR amplitude \pm 1 SEM for infusions of vehicle and CNQX (1.54 and $5 \mathrm{mM}$ ).

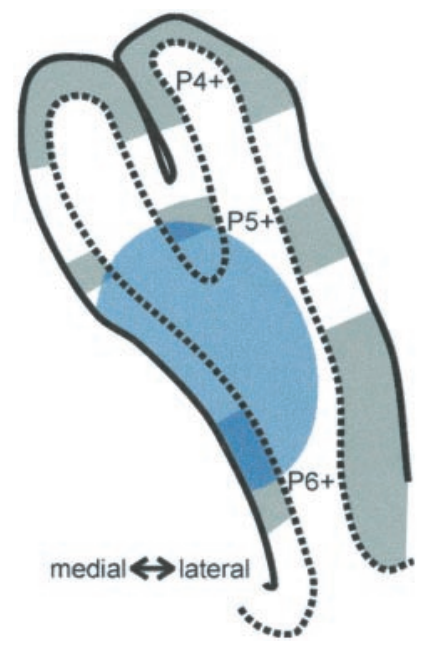

Figure 4. Zebrin II bands in rostral lobule HVI and the localization of a critical NMR control area. Zebrin-immunopositive bands $P 4+, P 5+$, and $P 6+$ are indicated, and the area important for $\mathrm{CR}$ performance, obtained by comparing the regional spread of CNQX with the magnitude of behavioral effects in individual animals (see Fig. 1), is shown in blue.

Fig. 4). Comparison of the CNQX autoradiographs with the zebrin immunohistochemistry from adjacent coronal sections revealed that behaviorally effective drug locations can be defined as within an area of rostral HVI bounded by zebrin zone P5+ dorsally and zebrin zone P6+ ventrally.

\section{DISCUSSION}

We have shown that blockade of cerebellar cortical AMPAkainate receptors with CNQX completely but reversibly blocks the production of previously established classically conditioned nictitating membrane responses. Lobule HVI was targeted in this study because our earlier analyses had shown its importance for NMR conditioning (Yeo et al., 1985b,c; Hardiman and Yeo, 1992; Yeo and Hardiman, 1992). Studies in the cat have shown that lobule HVI contains the principal eye blink control microzones, which receive climbing fiber inputs signaling periocular stimulation (Hesslow, 1994). In the present study, autoradiography and the ranking of behavioral effects indicate that, in the rabbit, these critical control areas are in the rostral part of lobule HVI. The dorsal and ventral boundaries of the critical region are close to Zebrin II-immunopositive bands corresponding to zones P5+ and P6+ in other species (Brochu et al., 1990). In five critical subjects, there was no detectable spread of CNQX into the deep nuclei, so the location and effects of the drug are very comparable with the location and effects of our earlier lesions. We confirm again that normal cerebellar cortical function in lobule HVI is critical for the expression of conditioned NM responses.

It should be noted that the location of the bound CNQX revealed by autoradiography may be an underestimate of the critical control area. CNQX will bind to AMPA-kainate receptors on a variety of cerebellar cortical neurons, including Purkinje, granule, stellate, and basket cells. CNQX binding on granule cells will disturb signaling through the granule cell ascending axon and its parallel fibers that can extend widely (Mugnaini, 1983). Thus, our autoradiography could have underestimated the effective cortical range of the CNQX. However, this underestimate is likely to be small. During phase 2 of the experiment, when infusion cannula locations were incremented in $0.5 \mathrm{~mm}$ steps, we saw distinctly different effects on CR frequencies at successive locations, indicating that the effective infusion sites were restricted, and distant effects were small.

The effects of cerebellar cortical lesions on NMR conditioning are reportedly rather variable. We have consistently seen severe losses of CRs for extended durations after full HVI lesions (Yeo et al., 1985b; Hardiman and Yeo, 1992; Yeo and Hardiman, 1992). Others have seen weaker or more transient impairments of CRs (McCormick and Thompson, 1984; Lavond et al., 1987), and pcd mutant mice have low levels of eye blink conditioning (Chen et al., 1996). If learning is very strongly established, with extensive preoperative conditioning, unilateral lesions have weaker 
effects, but bilateral HVI lesions severely impair CRs even in heavily overtrained subjects (Gruart and Yeo, 1995). At the conditioning levels used here, we would not expect bilateral infusions of the drug to have been necessary. The effects of localized CNQX infusions on NM CRs are strikingly similar to those we have previously reported after destructive lesions.

We cannot comment on the importance for NMR conditioning of other cerebellar cortical areas, including those within the anterior lobe that have been implicated in external eyelid conditioning (Perrett et al., 1992), because we have not systematically inactivated them. However, there was no evidence of shortlatency CRs after CNQX infusions in HVI, as has been reported for anterior lobe lesions. With the drug doses and conditioning parameters used in the present study, CR amplitudes were progressively attenuated with a corresponding increase in onset latencies before reaching zero amplitude.

Using a temporary inactivation of cerebellar cortical function, we have confirmed the critical importance of lobule HVI for the expression of NMR conditioning. CNQX infusions provide a window of inactivation (which can last between 21 and $77 \mathrm{~min}$, depending on concentration and localization) that can be used for further analysis. If the cerebellar cortex plays a critical role in acquisition, then its blockade before conditioning trials should prevent new learning. Inf usions of CNQX in lobule HVI provide a powerful new tool to test the role of the cerebellar cortex in the acquisition of simple motor learning.

The critical areas within lobule HVI are now better defined between Zebrin P5+ and P6+ in rostral HVI. This anatomical marker will be useful in future studies. In vitro analysis of the more dorsal parts of rostral HVI in cerebellar slices shows that there are NMR conditioning-specific increases in excitability of Purkinje cell dendrites (Schreurs et al., 1998). It will be important to see whether these or other changes can be found in those areas within HVI that have been shown in the present study to have a critical role in the control of conditioned responses.

\section{REFERENCES}

Albus JS (1971) A theory of cerebellar function. Math Biosci 10:25-61. Brochu G, Maler L, Hawkes R (1990) Zebrin II: a polypeptide antigen expressed selectively by Purkinje cells in the rat and fish cerebellum. J Comp Neurol 291:538-552.

Chen L, Bao S, Lockard JM, Kim JJ, Thompson RF (1996) Impaired classical eyeblink conditioning in cerebellar-lesioned and purkinje cell degeneration ( $p c d$ ) mutant mice. J Neurosci 16:2829-2838.

Gormezano I, Schneiderman N, Deaux E, Fuentes I (1962) Nictitating membrane: classical conditioning and extinction in the albino rabbit. Science 138:93-106.

Gruart A, Yeo CH (1995) Cerebellar cortex and eyeblink conditioning: bilateral regulation of conditioned responses. Exp Brain Res 104:431-448.

Hardiman MJ, Yeo CH (1992) The effect of kainic acid lesions of the cerebellar cortex on the conditioned nictitating membrane response in the rabbit. Eur J Neurosci 4:966-980.

Hardiman MJ, Ramnani N, Yeo CH (1996) Reversible inactivations of the cerebellum with muscimol prevent the acquisition and extinction of conditioned nictitating membrane responses in the rabbit. Exp Brain Res 110:235-247.

Hesslow G (1994) Correspondence between climbing fibre input and motor output in eyeblink-related areas in cat cerebellar cortex. J Physiol (Lond) 476:229-244.

Ito M (1998) Cerebellar learning in the vestibulo-ocular reflex. Trends Cognit Sci 2:313-321.

Krupa DJ, Thompson RF (1995) Inactivation of the superior cerebellar peduncle blocks expression but not acquisition of the rabbit's classically conditioned eye-blink response. Proc Natl Acad Sci USA 92:5097-5101.

Krupa DJ, Thompson JK, Thompson RF (1993) Localization of a memory trace in the mammalian brain. Science 260:989-991.

Lavond DG, Steinmetz JE, Yokaitis MH, Thompson RF (1987) Reacquisition of classical conditioning after removal of cerebellar cortex. Exp Brain Res 67:569-593.

Marr D (1969) A theory of cerebellar cortex. J Physiol (Lond) 202:437-470.

Mauk MD, Donegan NH (1997) A model of Pavlovian eyelid conditioning based on the synaptic organization of the cerebellum. Learn Mem 3:130-158.

McCormick DA, Thompson RF (1984) Cerebellum: essential involvement in the classically conditioned eyelid response. Science 223:296-299.

Mugnaini E (1983) The length of cerebellar parallel fibers in chicken and rhesus monkey. J Comp Neurol 220:7-15.

Nordholm AF, Thompson JK, Dersarkissian C, Thompson RF (1993) Lidocaine infusion in a critical region of cerebellum completely prevents learning of the conditioned eyeblink response. Behav Neurosci 107:882-886.

Perrett SP, Ruiz BP, Mauk MD (1992) Cerebellar cortex lesions disrupt learning-dependent timing of conditioned eyelid responses. J Neurosci 13:1708-1718.

Ramnani N, Yeo CH (1996) Reversible inactivations of the cerebellum prevent the extinction of conditioned nictitating membrane responses in rabbits. J Physiol (Lond) 495:159-168.

Schreurs BG, Gusev PA, Tomsic D, Alkon DL, Shi T (1998) Intracellular correlates of acquisition and long-term memory of classical conditioning in Purkinje cell dendrites in slices of rabbit cerebellar lobule HVI. J Neurosci 18:5498-5507.

Thach WT (1998) What is the role of the cerebellum in motor learning and cognition? Trends Cognit Sci 9:331-337.

Thompson RF, Krupa DJ (1994) Organization of memory traces in the mammalian brain. Annu Rev Neurosci 17:519-549.

Welsh JP, Harvey JA (1989) Cerebellar lesions and the nictitating membrane reflex: performance deficits of the conditioned and unconditioned response. J Neurosci 9:299-311.

Welsh JP, Harvey JA (1991) Pavlovian conditioning in the rabbit during inactivation of the interpositus nucleus. J Physiol (Lond) 444:459-480.

Welsh JP, Harvey JA (1998) Acute inactivation of the inferior olive blocks associative learning. Eur J Neurosci 10:3321-3332.

Yeo CH, Hardiman MJ (1992) Cerebellar cortex and eyeblink conditioning: a re-examination. Exp Brain Res 88:623-638.

Yeo CH, Hesslow G (1998) Cerebellum and conditioned reflexes. Trends Cognit Sci 9:322-330.

Yeo CH, Hardiman MJ, Glickstein M (1985a) Classical conditioning of the nictitating membrane response of the rabbit. I. Lesions of the cerebellar nuclei. Exp Brain Res 60:87-98.

Yeo CH, Hardiman MJ, Glickstein M (1985b) Classical conditioning of the nictitating membrane response of the rabbit. II. Lesions of the cerebellar cortex. Exp Brain Res 60:99-113.

Yeo CH, Hardiman MJ, Glickstein M (1985c) Classical conditioning of the nictitating membrane response of the rabbit. III. Connections of cerebellar lobule HVI. Exp Brain Res 60:114-126. 